\title{
Evaluation of "Candida score" in critically ill patients: a prospective, multicenter, observational, cohort study
}

\author{
Guillaume Leroy ${ }^{1}$, Fabien Lambiotte ${ }^{2}$, Didier Thévenin ${ }^{3}$, Christian Lemaire ${ }^{4}$, Erika Parmentier ${ }^{5}$, Patrick Devos ${ }^{6}$ and \\ Olivier Leroy ${ }^{1 *}$
}

\begin{abstract}
Introduction: Although prompt initiation of appropriate antifungal therapy is essential for the control of invasive Candida infections and an improvement of prognosis, early diagnosis of invasive candidiasis remains a challenge and criteria for starting empirical antifungal therapy in ICU patients are poorly defined. Some scoring systems, such as the "Candida score" could help physicians to differentiate patients who could benefit from early antifungal treatment from those for whom invasive candidiasis is highly improbable. This study evaluated the performance of this score in a cohort of critically ill patients.
\end{abstract}

Methods: A prospective, observational, multicenter, cohort study was conducted from January 2010 to March 2011 in five intensive care units in Nord-Pas de Calais, an area from North of France. All patients exhibiting, on ICU admission or during their ICU stay, a hospital-acquired severe sepsis or septic shock could be included in this study. The data collected included patient characteristics on ICU admission and at the onset of severe sepsis or septic shock. The "Candida score" was calculated at the onset of sepsis or shock. The incidence of invasive candidiasis was determined and its relationship with the value of the "Candida score" was studied.

Results: Ninety-four patients were studied. When severe sepsis or shock occurred, 44 patients had a score $=2,29$ patients had a score $=3,17$ patients had a score $=4$, and 4 patients had a score $=5$. Invasive candidiasis was observed in five (5.3\%) patients. One patient had candidemia, three patients had peritonitis, and one patient had pleural infection. The rates of invasive candidiasis was $0 \%$ in patients with score $=2$ or 3,17.6\% in patients with score $=4$, and $50 \%$ in patients with score $=5(p<0.0001)$.

Conclusions: Our results confirm that the "Candida score" is an interesting tool to differentiate among ICU patients who exhibit hospital-acquired severe sepsis or septic shock those would benefit from early antifungal treatment (score $>3$ ) from those for whom invasive candidiasis is highly improbable (score $\leq 3$ ).

\section{Introduction}

Invasive Candida infections are the most common invasive fungal infections, accounting for $70-90 \%$ of all invasive mycoses [1]. Among the causes of nosocomial bloodstream infections, Candida ranks number four in the United States [2]. Incidence of candidemia varies between 0.5 and 1.4 per 10,000 patient-days in hospital and between 2 and 6.9 per 1,000 admissions in the

\footnotetext{
* Correspondence: oleroy@ch-tourcoing.fr

${ }^{1}$ Service de Réanimation Médicale et Maladies Infectieuses, Centre Hospitalier de Tourcoing, 59208 Tourcoing, France

Full list of author information is available at the end of the article
}

intensive care unit (ICU) [3-7]. Invasive candidiasis is associated with high mortality, especially in ICUs [8-10]. Prompt initiation of appropriate antifungal therapy is essential for the control of invasive Candida infections and has been shown to reduce mortality [11-13].

Unfortunately, early diagnosis of invasive candidiasis remains a challenge, and criteria for starting empirical antifungal therapy in ICU patients are poorly defined. Recent IDSA guidelines suggest that "empirical antifungal therapy should be considered in critically ill patients with risk factors for invasive candidiasis and no other known cause of fever" [14]. Risk factors for invasive candidiasis 
are well identified [15]. However, these are so numerous that most ICU patients could be considered as exhibiting risk factors for invasive candidiasis. Obviously, widespread use of antifungal agents would be associated with substantially increased overall health care costs and emergence of resistance [16,17].

To both ensure appropriate and timely antifungal therapy and to avoid unnecessary use of antifungal agents, some authors have developed clinical prediction rules to identify ICU patients at high risk of candidiasis and for whom initiation of empirical antifungal therapy could be justified [18-20]. However, there are many concerns about these rules: high specificity but low sensitivity, no prospective validation, and complicated use.

In 2006, a Spanish group, using the database of the Estudio de Prevalencia de CANdidiasis project, identified four predictors of proven invasive Candida infection [21]. Based on these predictors, a score named "Candida score" was built. In 2009, the same group demonstrated a significant linear association between increasing values of the "Candida score" and the rate of invasive Candida infections [22]. Such a score could be useful to stratify the risk of proven Candida infection and differentiate patients who would benefit from early antifungal treatment from those for whom invasive candidiasis is highly improbable.

The goal of the present study was to evaluate, in a prospective and multicenter cohort of ICU patients developing hospital-acquired severe sepsis or septic shock, the performance of the "Candida score."

\section{Materials and methods Study population}

This prospective observational cohort study was performed from January 2010 to March 2011 in five ICUs (Lens, Lille, Maubeuge, Roubaix, and Tourcoing) in Nord-Pas de Calais, an area from the north of France. The study protocol was submitted to the Institutional Review Board for Lille University Hospital, which gave an approval with waiver of informed consent, in agreement with French regulations concerning observational studies that do not modify existing diagnosis or therapeutic strategies.

All patients exhibiting, on ICU admission or during their ICU stay, hospital-acquired severe sepsis or septic shock could be included in this study. Exclusion criteria were community-acquired infections, age $<18$ years, neutropenia defined as a total leukocyte count $<500 / \mathrm{mm}^{3}$, pregnant women and nursing mothers, and patients who were treated with antifungal drugs when severe sepsis or septic shock occurred.

\section{Study design}

The primary objective of this study was to determine the incidence of invasive candidiasis among included patients and to study the relationship between the presence of invasive candidiasis and the "Candida score" value at the onset of severe sepsis or septic shock. The secondary objective was to analyze the antifungal therapies instituted when severe sepsis or shock occurred and to determine their relationship with the "Candida score" value.

\section{Data collection, evaluation, and definition}

On ICU admission, demographic characteristics, underlying diseases, reason for ICU admission, and severity of illness were recorded by each investigator on a standardized report form. Underlying diseases included insulin-dependent diabetes mellitus, neurologic conditions, chronic obstructive pulmonary disease, chronic liver disease, chronic renal failure, congestive severe heart failure, and immunosuppression (prednisolone $>0.5 \mathrm{mg} / \mathrm{kg} / \mathrm{d}$ since more than 1 month, human immunodeficiency virus infection, cancer chemotherapy within the past 3 months, organ transplantation with ongoing immunosuppressant, bone marrow allograft or hematopoietic stem-cell transplantation, immunosuppressant, or anti-tumor necrosis factor).

According to diagnoses at the time of ICU admission, patients were classified as surgical (admission for the postoperative care of an elective or urgent surgical procedure), trauma (admission because of trauma-related acute lesions), or medical (all other patients). Severity of illness on admission in ICU was assessed by using the Simplified Acute Physiology Score (SAPS) II and the Sepsis-related Organ Failure Assessment (SOFA) score [23,24].

During the ICU stay, screening for Candida colonization was performed twice weekly by routine samples from tracheal aspirates and urine. Other samples from peripheral blood, vascular catheters, wound or drainage exudates, or other infected foci could be obtained at the discretion of the attending physician. Samples were processed by the different clinical microbiology laboratories of the participating hospitals.

When hospital-acquired severe sepsis or septic shock occurred, components of the "Candida score" and therapeutic data were collected. Severe sepsis and septic shock were defined according to international sepsis definition [25]. They were considered as hospital-acquired when infection was neither present nor incubating at the time of admission to the acute care setting [26]. Components of "Candida score" were severe sepsis, total parenteral nutrition, surgery, and multifocal Candida colonization. These components were defined according to criteria proposed by Leon et al. [21]. The "Candida score" was calculated by adding points provided by each component as proposed by Leon et al. in their second study [22]. In our cohort, the minimum value of the score was 2 points for all patients, because severe sepsis or septic shock were inclusion criteria. The total score was obtained by 
adding 1 point for each remaining variable, total parenteral nutrition, surgery, and multifocal Candida colonization. Candida colonization was considered multifocal when Candida species were isolated, at the same moment, from two or more noncontiguous foci, even if Candida species were different. In some patients, data about Candida colonization were unknown when severe sepsis or septic shock occurred (i.e., patients admitted in ICU from another ward or another hospital). Samples from tracheal aspirates or urine were obtained at admission and the final Candida score was only determined when cultures results were available. Finally, the decision to treat a patient with antifungal drugs during the course of this observational study was at the discretion of each attending physician. In all cases, the date of starting antifungal treatment and antifungal agents administered were recorded.

In all patients, usual risk factors for invasive Candida infection, not included in the "Candida score," such as exposition to invasive devices (endotracheal tube for mechanical ventilation, central venous catheter, implantable drug delivery system, urinary catheter), antibiotic therapy for more than 5 days within the past 2 weeks, immunosuppression, renal failure, and insulin-dependent diabetes mellitus were recorded.

Invasive candidiasis was defined according to usual criteria, such as those proposed by Leon et al. [21,22]. Briefly, candidemia was defined by at least one positive blood culture, and peritonitis was diagnosed on the basis of macroscopic findings and direct examination or positive culture for Candida of the peritoneal fluid collected during surgical procedure. Isolation of Candida species from normally sterile body fluids, such as pleural or pericardial fluid, also was considered as definite criteria of invasive candidiasis. Patient mortality at the time of ICU discharge was determined.

\section{Statistics}

Variables were expressed as median values and ranges for numerical variables and as frequencies and percentages for categorical variables. Categorical variables were compared using the Chi-square and Fisher's exact tests. Numerical variables were compared using parametric test (Student's test) or nonparametric tests (Wilcoxson, Kruskal-Wallis) according to the sample size of the groups, the number of groups, and the normality of parameters. Statistical significance was accepted at the 5\% level.

\section{Results}

Ninety-four patients were included. Main patients' characteristics on ICU admission are summarized in Table 1. At inclusion, 73 patients exhibited septic shock and 21 had severe sepsis. The median time between ICU
Table 1 Main patients' characteristics on ICU admission

\begin{tabular}{ll}
\hline Characteristics & \\
\hline Mean age, yr $( \pm$ SD) & $62.8( \pm 9.9)$ \\
Male/female ratio & $71 / 23$ \\
Mean SAPS $( \pm$ SD) & $51.1( \pm 2.12)$ \\
Mean SOFA score $( \pm$ SD) & $8.32( \pm 1.12)$ \\
Diagnosis on ICU admission, no. (\%) & \\
Medical & $68(72.3)$ \\
Surgical & $25(26.6)$ \\
Abdominal surgery & $16(17)$ \\
Trauma & $1(1.1)$ \\
Underlying diseases, no. (\%) & \\
Congestive severe heart failure & $15(16)$ \\
Insulin-dependent diabetes mellitus & $11(11.7)$ \\
Chronic obstructive pulmonary disease & $26(27.7)$ \\
Chronic liver disease & $12(12.8)$ \\
Chronic neurologic disease & $10(10.6)$ \\
Chronic renal failure & $11(11.7)$ \\
Immunosuppression & $9(9.6)$ \\
\hline
\end{tabular}

admission and occurrence of shock or severe sepsis was 7 (range, -1 to 37 ) days. Mean SOFA score was $9.9 \pm 2.12$.

When severe sepsis or shock occurred, 27 patients had a total parenteral nutrition, 31 had undergone a surgical procedure immediately before or during ICU stay, and 17 had a multifocal Candida colonization. Candida species were found in urine $(n=17)$ and tracheal aspirates ( $\mathrm{n}=17)$ cultures. Thirty-seven Candida isolates were identified: C. albicans $(\mathrm{n}=30), C$. tropicalis $(\mathrm{n}=3)$, C. parapsilosis $(\mathrm{n}=2)$, and other species $(\mathrm{n}=2)$. Calculated and distribution of "Candida scores" was as follows: 44 patients with no risk factor had a score $=2 ; 29$ patients with a lone risk factor (total parenteral nutrition $\mathrm{n}=8$, surgery $\mathrm{n}=10$, and multifocal Candida colonization $\mathrm{n}=11$ ) had a score $=3$; 17 patients with two risk factors (total parenteral nutrition $\mathrm{n}=15$, surgery $\mathrm{n}=$ 17, and multifocal Candida colonization $\mathrm{n}=2$ ) had a score $=4$. Finally, four patients had all risk factors and a score $=5$.

Numerous other risk factors for invasive Candida infection were present and are reported in Table 2, broken by "Candida score" value. Among the 94 patients, severe sepsis or septic shock were due to or associated with invasive candidiasis in $5(5.3 \%)$ patients. One patient had $C$. parapsilosis candidemia, three patients had C. albicans peritonitis, and one patient had C. tropicalis pleural infection. The patient with $C$. parapsilosis candidemia had C. albicans-positive tracheal aspirates cultures and C. parapsilosis-positive urine cultures. Among the three patients with peritonitis, only one had multifocal Candida colonization with C. albicans-positive tracheal aspirates and urine cultures. The patient 
Table 2 Risk factors for invasive candidiasis, according to the value of "Candida score"

\begin{tabular}{lllll}
\hline Risk factors & $\begin{array}{l}\text { Candida score }=\mathbf{2} \\
(\mathbf{n = 4 4 )}\end{array}$ & $\begin{array}{l}\text { Candida score = } \\
(\mathbf{n}=\mathbf{2 9})\end{array}$ & $\begin{array}{l}\text { Candida score }=\mathbf{4} \\
(\mathbf{n}=\mathbf{1 7})\end{array}$ & $\begin{array}{l}\text { Candida score }=\mathbf{5} \\
\mathbf{( n = 4 )}\end{array}$ \\
\hline Severe sepsis or septic shock & 44 & 29 & 17 & 4 \\
Total parenteral nutrition & 0 & 8 & 15 & 4 \\
Surgery & 0 & 10 & 17 & 4 \\
Multifocal Candida colonization & 0 & 11 & 2 & 4 \\
Invasive mechanical ventilation & 30 & 23 & 11 & 2 \\
Central venous catheter & 39 & 27 & 15 & 4 \\
Urinary catheter & 42 & 27 & 17 & 4 \\
Antibiotherapy > 5 days within the past 2 weeks & 39 & 25 & 14 & 4 \\
Renal replacement therapy & 8 & 10 & 4 & 1 \\
Insulin-dependent diabetes mellitus & 7 & 4 & 0 & 0 \\
Immunosuppression & 4 & 3 & 2 & 0 \\
\hline
\end{tabular}

with C. tropicalis pleural infection had C. albicans-positive tracheal aspirates and urine cultures.

The rates of invasive candidiasis according to the "Candida score" was $0 \%$ in the 44 patients with score $=$ 2 and the 29 patients with score $=3,17.6 \%(n=3)$ in the 17 patients with score $=4$, and $50 \%(n=2)$ in the 4 patients with score $=5$. The association between increasing values of the "Candida score" and the rate of invasive candidiasis is statistically significant $(p<$ $0.0001)$. In patients with a "Candida score" $\leq 3$, no invasive candidiasis was observed. The positive and negative predictive values of this cutoff value of the "Candida score" were $23.8 \%$ and $100 \%$, respectively. Among the 68 patients with medical diagnosis on ICU admission, 4 had a "Candida score" $>3$ and 1 of 4 exhibited an invasive candidiasis. Among the 25 patients with a surgical diagnosis on ICU admission, 17 had a "Candida score" $>3$ and 4 of 17 had an invasive candidiasis. Although the number of patients with a "Candida score" $>3$ was higher in surgical than medical patients $(p<0.0001)$, the rate of invasive candidiasis was similar for surgical and medical patients with a "Candida score" >3 (4/17 vs. $1 / 4 ; p=1)$. When severe sepsis or septic shock occurred, 19 (20\%) patients received empiric antifungal treatment with fluconazole in 12 cases and caspofungin in 7 cases. Empiric antifungal treatment was initiated in 1 of $44(2.3 \%)$ patients with a "Candida score" $=2,8$ of $29(27.6 \%)$ patients with a "Candida score" $=3,7$ of 17 $(41.2 \%)$ patients with a "Candida score" $=4$, and 3 of 4 $(75 \%)$ patients with a "Candida score" = 5. All five patients with invasive candidiasis received, when severe sepsis or septic shock occurred, empirical antifungal therapy.

Forty-six (49\%) patients died during their ICU stay. Among the 68 patients with a medical diagnosis on ICU admission, 32 (47\%) died, whereas among the 25 patients with a surgical diagnosis on ICU admission, 14 (56\%) died $(p=0.45)$. Mortality rates according to the values of the "Candida score" and the empiric initiation of antifungal treatment are reported in Table 3 . No statistically significant difference was observed. Among the 73 patients with a "Candida score" $\leq 3,33$ (45\%) died, whereas among the 21 patients with a score $>3,13(62 \%)$ died $(p$ $=0.17)$. An empiric antifungal treatment was instituted in 19 patients, and 10 (53\%) of them died. Thirty-six $(48 \%)$ of the 75 patients who did not receive empiric antifungal treatment died. Such a difference was not statistically significant $(p=0.72)$. Finally, among the 21 patients with a "Candida score" $>3$, mortality was not different for patients who received or did not receive empiric antifungal treatment $(6 / 10$ vs. $7 / 11 ; p=1)$.

\section{Discussion}

This prospective cohort study confirms that the "Candida score" is an interesting tool to differentiate, among ICU patients with hospital-acquired severe sepsis or septic shock, those who would benefit from early antifungal treatment (score $>3$ ) from those for whom invasive candidiasis is highly improbable (score $\leq 3$ ).

For patients who develop, during ICU stay, severe sepsis or septic shock, it has been demonstrated a few decades ago that prompt and adequate antimicrobial treatment is associated with prognosis improvement. Moreover, it was demonstrated that bloodstream infections due to Candida species were independently associated with administration of inadequate antimicrobial treatment [27]. These results led physicians to question the interest of adding an antifungal agent to the empirical antibiotic regimen administered to patients with severe sepsis or septic shock. However, criteria for starting empirical antifungal therapy in ICU patients are poorly defined and recent IDSA guidelines suggesting that "empirical antifungal therapy should be considered in critically ill patients with risk factors for invasive candidiasis and no other known cause of fever" could lead to an overuse of antifungal agents. The "Candida score" 
Table 3 Severity scores and mortality, according to the value of "Candida score"

\begin{tabular}{|c|c|c|c|c|c|}
\hline & $\begin{array}{l}\text { Candida score }=2 \\
(\mathrm{n}=44)\end{array}$ & $\begin{array}{l}\text { Candida score }=3 \\
(\mathrm{n}=29)\end{array}$ & $\begin{array}{l}\text { Candida score }=4 \\
(\mathrm{n}=17)\end{array}$ & $\begin{array}{l}\text { Candida score }=5 \\
(\mathrm{n}=4)\end{array}$ & $p$ \\
\hline Mean SAPS \pm SD & $51.61 \pm 16.79$ & $49.72 \pm 15.93$ & $52.18 \pm 21.84$ & $52 \pm 8.04$ & 0.981 \\
\hline Mean SOFA score \pm SD & $8.8 \pm 3.3$ & $7.41 \pm 3.27$ & $8.59 \pm 4.71$ & $8.5 \pm 1.73$ & 0.583 \\
\hline Overall mortality & $22(50 \%)$ & $11(38 \%)$ & $11(64.7 \%)$ & $2(50 \%)$ & 0.37 \\
\hline \multicolumn{6}{|c|}{ Mortality according to the initiation of an empiric antifungal treatment } \\
\hline & Candida score $=2$ & Candida score $=3$ & Candida score $=4$ & Candida score $=5$ & $p$ \\
\hline Yes & $1 / 1$ & $3 / 8$ & $4 / 7$ & $2 / 3$ & 0.59 \\
\hline No & $21 / 43$ & $8 / 21$ & $7 / 10$ & $0 / 1$ & 0.3 \\
\hline
\end{tabular}

could overcome the dilemma between overuse, associated with increased health costs and development of resistance, and underuse, associated with prognosis impairment of critically ill patients.

In 2006, Leon et al. reported a prospective, cohort, observational, multicenter study of 1,669 adult ICU patients admitted to 73 medical-surgical Spanish ICUs between May 1998 and January 1999 [21]. They identified four independent factors associated with a greater risk for proven invasive Candida infection. A bedside scoring system called "Candida score" was built as follows: Candida score $=0.908 \times$ (total parenteral nutrition) $+0.997 \times$ (surgery) $+1.112 \times$ (multifocal Candida species colonization $)+2.038 \times($ severe sepsis $)$. All variables were coded 1 if present and 0 if absent. According to receiver operating characteristics (ROC) curve and area under the ROC curve, a score $>2.5$ accurately identified patients with the greater risk of proven invasive Candida infection (sensitivity $81 \%$, specificity $74 \%$ ). In 2009, Leon et al. prospectively studied 1,107 adult ICU patients admitted between April 2006 and June 2007 in 36 medical-surgical ICU in Spain, France, and Argentina [22]. They used a rounded "Candida score" calculated as follows (all variables were coded 0 if absent and 1 if present): $1 \times$ (total parenteral nutrition) $+1 \times$ (surgery) $+1 \times$ (multifocal Candida colonization) $+2 \times$ (severe sepsis). They demonstrated a linear and significant association between increasing values of the "Candida score" and the rate of invasive candidiasis. The incidence rate was $2.3,8.5,16.8$, and 23.6 when the score was $<3,3,4$, and 5 , respectively. They concluded that invasive candidiasis is highly improbable in patients with "Candida score" $<3$.

Our results are in accordance with Leon's data. The incidence rates of invasive candidiasis were $0 \%, 0 \%$, $17.6 \%$, and $50 \%$ in patients with scores equal to $2,3,4$, and 5 , respectively. A linear and significant association between increasing values of the "Candida score" and the rate of invasive candidiasis was observed, and no invasive candidiasis occurred in patients with scores $<3$. Moreover, no invasive candidiasis was observed in patients with a "Candida score" $=3$. Interestingly, we also can underline that the performances of this score are similar in medical and surgical patients. Surgical patients exhibit more often a "Candida score" $>3$ than medical patients, but the rate of invasive candidiasis is similar in surgical and medical patients with a "Candida score" $>3$.

Therapeutic decisions of intensivists in our group could be discussed. Decision to initiate antifungal drugs during this observational study was at the discretion of each attending physician. Nevertheless, we observed a relationship between initiation of antifungal agents and value of the "Candida score." Frequency of antifungal empirical therapy were $2.3 \%, 27.6 \%, 41.2 \%$, and $75 \%$ in patients with scores equal to $2,3,4$, and 5 , respectively. In our opinion, this is rather satisfying because most patients with highly improbable invasive candidiasis did not receive antifungal drugs, whereas early empirical antifungal treatment was initiated in most patients who would benefit from it. However, the fact that only a quarter of patients with score $=3$ received an empiric antifungal treatment merits some comments. In our series, all included patients exhibited severe sepsis or septic shock and, therefore, had a "Candida score" always at least equal to 2. Initiation of empirical antifungal treatment to all patients with another risk factor (surgery or total parenteral nutrition or multifocal Candida colonization) probably seemed to be excessive to most intensivists of our group. The absence of invasive candidiasis, among the 29 patients with a "Candida score" $=3$, retrospectively confirm the appropriateness of their decision.

This study has numerous limitations. First, the number of included patients is low compared with the number of patients studied by Leon and his group [21,22]. The inclusion of patients with severe sepsis or septic shock rather than all ICU admitted patients, and the low number of ICU participating to this cohort study explain this fact. Second, only five invasive candidiasis and, among them, only one candidemia were observed in this cohort. The low number of invasive candidiasis can be explained, first, with some exclusion criteria such as neutropenia, and, second, with the setting of the ICU; 
four of them were in a secondary care hospital and only one in a university hospital. Third, in some patients, the "Candida score" could not be calculated when sepsis or shock occurred, because some mycological data were lacking. However, this only reflects the shortcomings of a real-life study and represents one limit to the practical use of the score.

\section{Conclusions}

Our study confirms the clinical relevance of the "Candida score" in patients with hospital-acquired severe sepsis or septic shock. This score can differentiate patients who would benefit from early antifungal treatment from those for whom invasive candidiasis is highly improbable.

\section{Acknowledgements}

The authors thank Serge Alfandari for assistance with manuscript preparation

\section{Author details}

${ }^{1}$ Service de Réanimation Médicale et Maladies Infectieuses, Centre Hospitalier de Tourcoing, 59208 Tourcoing, France ${ }^{2}$ Service de réanimation, Centre Hospitalier de Maubeuge 59, France ${ }^{3}$ Service de réanimation, Centre Hospitalier de Lens 62, France ${ }^{4}$ Service de réanimation médicale, Centre Hospitalier de Roubaix 59, France ${ }^{5}$ Service des urgences respiratoires et de réanimation médicale, Hôpital Calmette, CHRU de Lille 59, France ${ }^{6}$ Département de biostatistiques, CHRU de Lille 59, France

\section{Authors' contributions}

$G L$ contributed to the design of the study, collected the data, and wrote the manuscript. FL, DT, CL, and EK collected the data. PD performed the statistical analysis. OL contributed to the design of the study and wrote the manuscript. All the authors read and approved the final manuscript.

\section{Competing interests}

The authors declare that they have no competing interests.

Received: 28 September 2011 Accepted: 30 November 2011 Published: 30 November 2011

\section{References}

1. Lamagni TL, Evans BG, Shigematsu M, Johnson EM: Emerging trends in the epidemiology of invasive mycoses in England and Wales (1990-9). Epidemiol Infect 2001, 126:397-414.

2. Wisplinghoff $H$, Bischoff $T$, Tallent SM, Seifert $H$, Wenzel RP, Edmond MB: Nosocomial bloodstream infections in US hospitals: analysis of 24,179 cases from a prospective nationwide surveillance study. Clin Infect Dis 2004, 39:309-317.

3. Marchetti O, Bille J, Fluckiger U, Eggimann P, Ruef C, Garbino J, Calandra T, Glauser MP, Täuber MG, Pittet D, Fungal Infection Network of Switzerland: Epidemiology of candidemia in Swiss tertiary care hospitals: secular trends, 1991-2000. Clin Infect Dis 2004, 38:311-320.

4. Gudlaugsson O, Gillespie S, Lee K, Vande Berg J, Hu J, Messer S, Herwaldt L, Pfaller M, Diekema D: Attributable mortality of nosocomial candidemia, revisited. Clin Infect Dis 2003, 37:1172-1177.

5. Charles PE, Doise JM, Quenot JP, Aube H, Dalle F, Chavanet P, Milesi N, Aho LS, Portier H, Blettery B: Candidemia in critically ill patients: difference of outcome between medical and surgical patients. Intensive Care Med 2003, 29:2162-2169.

6. Nolla-Salas J, Sitges-Serra A, Leon-Gil C, Martínez-González J, LeónRegidor MA, Ibáñez-Lucía P, Torres-Rodríguez JM: Candidemia in nonneutropenic critically ill patients: analysis of prognostic factors and assessment of systemic antifungal therapy. Study Group of Fungal Infection in the ICU. Intensive Care Med 1997, 23:23-30.
7. Kett DH, Azoulay E, Echeverria PM, Vincent JL, Extended Prevalence of Infection in ICU Study (EPIC II) Group of Investigators: Candida bloodstream infections in intensive care units: analysis of the extended prevalence of infection in intensive care unit study. Crit Care Med 2011, 39:665-670.

8. Leleu G, Aegerter P, Guidet B: Systemic candidiasis in intensive care units: a multicenter, matched-cohort study. J Crit Care 2002, 17:168-175.

9. Leroy O, Gangneux JP, Montravers P, Mira JP, Gouin F, Sollet JP, Carlet J, Reynes J, Rosenheim M, Regnier B, Lortholary O, AmarCand Study Group: Epidemiology, management, and risk factors for death of invasive Candida infections in critical care: a multicenter, prospective, observational study in France (2005-2006). Crit Care Med 2009, 37:1612-1618.

10. Montravers P, Mira JP, Gangneux JP, Leroy O, Lortholary O, for the AmarCand Study Group: A multicentre study of antifungal strategies and outcome of Candida spp. peritonitis in intensive-care units. Clin Microbiol Infect 2011, 17:1061-1067.

11. Almirante B, Rodriguez D, Park BJ, Cuenca-Estrella M, Planes AM, Almela M, Mensa J, Sanchez F, Ayats J, Gimenez M, Saballs P, Fridkin SK, Morgan J, Rodriguez-Tudela JL, Warnock DW, Pahissa A, Barcelona Candidemia Project Study Group: Epidemiology and predictors of mortality in cases of Candida bloodstream infection: results from population-based surveillance, Barcelona, Spain, from 2002 to 2003. J Clin Microbiol 2005, 43:1829-1835.

12. Morrell M, Fraser VJ, Kollef $\mathrm{MH}$ : Delaying the empiric treatment of Candida bloodstream infection until positive blood culture results are obtained: a potential risk factor for hospital mortality. Antimicrob Agents Chemother 2005, 49:3640-3645.

13. Parkins MD, Sabuda DM, Elsayed S, Laupland KB: Adequacy of empirical antifungal therapy and effect on outcome among patients with invasive Candida species infections. J Antimicrob Chemother 2007, 60:613-618.

14. Pappas PG, Kauffman CA, Andes D, Benjamin DK Jr, Calandra TF, Edwards JE Jr, Filler SG, Fisher JF, Kullberg BJ, Ostrosky-Zeichner L, Reboli AC, Rex JH, Walsh TJ, Sobel JD, Infectious Diseases Society of America: Clinical practice guidelines for the management of candidiasis: 2009 update by the Infectious Diseases Society of America. Clin Infect Dis 2009, 48:503-535.

15. Guery BP, Arendrup MC, Auzinger G, Azoulay E, Borges Sá M, Johnson EM, Müller E, Putensen C, Rotstein C, Sganga G, Venditti M, Zaragoza Crespo R, Kullberg BJ: Management of invasive candidiasis and candidemia in adult non-neutropenic intensive care unit patients: part I. Epidemiology and diagnosis. Intensive Care Med 2009, 35:55-62.

16. Olaechea PM, Palomar M, León-Gil C, Alvarez-Lerma F, Jordá R, Nolla-Salas J León-Regidor MA, EPCAN Study Group: Economic impact of Candida colonization and Candida infection in the critically ill patient. Eur J Clin Microbiol Infect Dis 2004, 23.323-330.

17. Hof $\mathrm{H}$ : Will resistance in fungi emerge on a scale similar to that seen in bacteria? Eur J Clin Microbiol Infect Dis 2008, 27:327-334.

18. Paphitou NI, Ostrosky-Zeichner L, Rex JH: Rules for identifying patients at increased risk for candidal infections in the surgical intensive care unit: an approach to developing practical criteria for systematic use in antifungal prophylaxis trials. Med Mycol 2005, 43:235-243.

19. Ostrosky-Zeichner L, Sable C, Sobel J, Alexander BD, Donowitz G, Kan V, Kauffman CA, Kett D, Larsen RA, Morrison V, Nucci M, Pappas PG, Bradley ME, Major S, Zimmer L, Wallace D, Dismukes WE, Rex JH: Multicenter retrospective development and validation of a clinical prediction rule for nosocomial invasive candidiasis in the intensive care setting. Eur J Clin Microbiol Infect Dis 2007, 26:271-276.

20. Shorr AF, Tabak YP, Johannes RS, Sun X, Spalding J, Kollef MH: Candidemia on presentation to the hospital: development and validation of a risk score. Crit Care 2009, 13:R156.

21. León C, Ruiz-Santana S, Saavedra P, Almirante B, Nolla-Salas J, AlvarezLerma F, Garnacho-Montero J, León MA, EPCAN Study Group: A bedside scoring system (Candida score) for early antifungal treatment in nonneutropenic critically ill patients with Candida colonization. Crit Care Med 2006, 34:730-737.

22. León C, Ruiz-Santana S, Saavedra P, Galván B, Blanco A, Castro C, Balasini C, Utande-Vázquez A, González de Molina FJ, Blasco-Navalproto MA, López MJ, Charles PE, Martín E, Hernández-Viera MA, Cava Study Group: Usefulness of the "Candida score" for discriminating between Candida colonization and invasive candidiasis in non-neutropenic critically ill patients: a prospective multicenter study. Crit Care Med 2009, 37:1624-1633. 
23. Le Gall JR, Lemeshow S, Saulnier F: A new Simplified Acute Physiology Score (SAPS II) based on a European/North American multicenter study. JAMA 1993, 270:2957-2963.

24. Vincent JL, Moreno R, Takala J, Willatts S, De Mendonça A, Bruining H, Reinhart CK, Suter PM, Thijs LG: The SOFA (Sepsis-related Organ Failure Assessment) score to describe organ dysfunction/failure. Intensive Care Med 1996, 22:707-710.

25. Levy MM, Fink MP, Marshall JC, Abraham E, Angus D, Cook D, Cohen J, Opal SM, Vincent $J$, Ramsay G, International Sepsis Definitions Conference: 2001 Crit Care Med/ESICM/ACCP/ATS/SIS International Sepsis Definitions Conference. Intensive Care Med 2003, 29:530-538.

26. Horan TC, Andrus M, Dudeck MA: CDC/NHSN surveillance definition of health care-associated infection and criteria for specific types of infections in the acute care setting. Am J Infect Control 2008, 36:309-332.

27. Ibrahim EH, Sherman G, Ward S, Fraser VJ, Kollef MH: The influence of inadequate antimicrobial treatment of bloodstream infections on patient outcomes in the ICU setting. Chest 2000, 118:146-155.

doi:10.1186/2110-5820-1-50

Cite this article as: Leroy et al:: Evaluation of "Candida score" in critically ill patients: a prospective, multicenter, observational, cohort study.

Annals of Intensive Care 2011 1:50.

\section{Submit your manuscript to a SpringerOpen ${ }^{\mathcal{O}}$ journal and benefit from:}

- Convenient online submission

- Rigorous peer review

- Immediate publication on acceptance

- Open access: articles freely available online

- High visibility within the field

- Retaining the copyright to your article

Submit your next manuscript at $\gg$ springeropen.com 